\title{
Inestabilidad tensional y embarazo
}

\author{
Por el docior Camlos R. Sillya Mojica \\ Ex-Jefe de Clínica Obstetrica.
}

Con este título comentamos tanto una historia clínica como algunas particularidades de la tensión arterial en el embarazo.

Se trata de una primigestante atendida en el ICSS (carnet No. 116331). l.dad: 23 años. Profesión: enfermera. Casada hace 11 meses. Antecedentes pawoligicos generales: sin importancia.

Antecedentes ginecológicos: normales. Ultima regla: octubre $20 / 51$. Fe(hia probable del parto: julio 3052 .

Examen general: (Mayo 2 52). Normales todos sus organos y aparatos Primigestante de 61/2 meses. Feto vivo. Serología negativa. Orina normal. Radiogralia pulmonar, negativa para TBC.

Mayo 30: Consulta por contracciones uterinas algo dolorosis. TA: 130/80; pulso 76; sin edemas. Para prevenir el parto prematuro se formulan sedantes y (peme físico.

Junio 13: Llega al Servicio de Admisión de la Clinica Primero de Mavo s. Fe anotan estos datos: dolor abdominal vago, permancnte, localizado en fas anmas umbilical y epigástrica. Dolor en la región sacra, cefalea persistente desde ince 10 dias. TA: 135,90; pulso: 80; ACI: 28 cent. TV: cucllo largo y cerra d.. Sc hospitaliza.

Nos informan del caso y nos hacen anotar la ligera alza de la TA y la ce l.lka. La examinamos una hora más tarde y encontramos los mismos datos de admisión: contracciones uterinas muy espaciadas; feto vivo en $\mathrm{Ol}$, móvil, pero anotamos una cifra alarmante para la TA, de 170/90, tomada con tensiómetro de mercurio. Es decir, que en el curso de una hora habia subido la TA en form.l exagerada.

Ante estos hechos hacemos diagnéstico de impresión de Preeclampsia grave, 1 prescribimos el siguiente tratamicnto: Fenergan, 1 am. i. m. cada 6 horas; - comar TA y pulso cada 6 horas; medir la cantidad de orina climinada en 24 ho. ras; dieta hipoproteica e hipoclorurada; pedir exámenes de laboratorio: parcial de orina; NPN y glicerina. Todas estas medidas son aplicadas de inmediato.

A las $5 \mathrm{p}$. $\mathrm{m}$. del mismo día, interesados por controlar la paciente y conocer los resultados del laboratorio la visitamos y anotamos con sorpresa una TA 
de $110 / 70$, con un examen de orina aceptable (huellas de albúmina; piocitos + ; hematies ++ ; bacterias + .

Como dudamos que este descenso espectacular de la TA se hubiera debido a la acción de una sola ampolleta de Fenergán, resolvemos hacer controles de la TA con pocos minutos de intervalo y por distintas personas.

TA a las 5:20 p.m.: 150100 (tomada por el interno).

TA a las 5:30 p.m.: 170100 (tomada por mí).

TA a las 5:40 p.m.: 11070 (tomada por la enfermera).

Ante estas notorias oscilaciones de la 'TA y con un examen de orina leve mente anormal apenas, modificamos el diagnóstcio anotado unas horas antes y pensamos en la posibilidad de un estado de inestabilidad tensional, cuya etiolo gía no es clara por el momento; dejamos como único tratamiento el fenergán inyectado cada 6 horas, hasta el siguiente dia, suspendemos todas las demás medidas.

Junio 14.-10:30 a. m.-Ha presentado contracciones uterinas poco dolorosas. TV: no hay borramiento ni dilatación. Se ordena suspender el fenergán, dar dieta libre, controlar TA y pulso; avisar si inicia trabajo regular.

TA a la 1 a.m.: $160 / 100$.

TA a las 7 a. m.: $160 / 100$.

TA a las 7 p. m.: $150 / 100$.

A las $7 \mathrm{p}$. m. el trabajo se hizo francamente regular.

Junio 15.-En este día se presenta el parto, espontáneo, normal; trabajo regular de 9 horas de duracion; feto femenino de $2.100 \mathrm{gr}$ x $46 \mathrm{cmts}$. Presentación OlA. Episiotomía. Anestesia general con ciclo para el desprendimiento $\mathrm{y}$ local para procaína, para la sutura de la episiotomía.

El feto tiene pie chapín unilateral; había expulsado bastante meconio por una circular muy apretadia en el cuello; presenta asfixia neonatorum medianamente grave; se reanima bien, con la aspiración de mucosidades e inhalaciones de ()2. Pasa en buen estado al servicio de prematuros.

TA antes de entrar a la sala de partos: 120/85.

TA después del parto: $138 / 90$.

Se preseribe lo siguiente para el puerperio: ergotrato 2 comp. al dia; sul fadiazina 8 comp. diarios por 2 dias; cibalgina en comprimidos para cl dolor.

TA a las 8 p. m.: 10080 .

Junio 16.--Paciente en buen estado. Llegan exámenes de laboratorio con resultados normales (NPN, glicemia, uricemia).

Junio 17.-. Paciente en buen estado.

TA: $160 / 95$.

Junio 18.-Paciente en buen estado. Por la noche la TA sube a 190/110 con pulso de 108 al minuto, sin fenómenos subjetivos de ninguna clase. Se or dena una cápsula de seconal y nuevo examen de orina.

Junio 19.-Paciente en buen estado. TA: 160/110. Se ordena suspender el ergotrato y dar un comprimido de gardenal a mañana y noche. El examen de orina indica huellas de albúmina y de glucosa, hematies $++t$. 
1 A a las $+1 / 2$ p. m.: 170,120 .

TA a las 10 p. m.: 180110 .

Junio 20.-Paciente en buen estado. Congestion mamaria por la llegada k. I. leche.

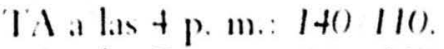

1 1. I.: 7 p. m.: 160110 .

lunii) 21.- Paciente en buen estade

lunio 22. Paciente en buenas condiciones generales Se le firma la salida.

\section{Cominiarios}

Anotamos que para un mejor estudio del caso hacen falta algunos exáme nes de laboratorio, tales como dato de fondo de ojo, metabolismo basal, y recuento de Addis. No se practicaron por factores particulares de la clínica que impicten su pronta ejecución.

Este caso nos induce a comentar algunas particularidades de la afección hipertensiva. Esta puede existir desde antey del embarazo o iniciarse en el curso de cute. En ella no hay signos ni sintomas de afección renal ni tampoco mayores alwraciones en los fondos oculares, por to nenos en las formas leves, porque en la forma maligna sí se aprecia retinitis angio espástica, edema papilar y estrechamicnto espástico y orgánico de las arteriolas. Además, no hay oscilaciones tan notorias de la TA y si se presentan, se efectúan sicmpre sobre un estado más 1 menos permanente de hipertension. Es cierto que en el comienzo de la hiper temion esencial, a veces hay un periodo de grandes oscilaciones de la TA, Ilamacle periodo de inestabilidad tensional ${ }^{2}$ que puede iniciarse en cualyuier époa de la vida; permanece por 8 o 10 anos para evolucionar luego al estado de hipertensión permanente.

Respecto de la afeccion renal, como es sabide, manifestamos que en ella cisten datos de lesion renal anterier al cmbarazo, inclusendo la determinada pen celampsia en embarazos pasados, o dato de un factor tosico o infeccioss co "Wntente con la gravidez que determine lesion aguda del rinon. In cstos casos l.t hipertension aparece desde el principio del embarazo o coexistiendo con el lactor téxico o infeccioso sea cual fuere la edad del embaraze. Es frecuente en los casos de lesión renal las alteraciones de la vision, tales como disminución de la agudeza visual, fosfenos, etc.

En los exámenes practicados a la paciente los únicos indices de lesión re nal son huellas de albumina y hematies ++ en la orina (junio 13), indices leves por cierto, antes del parto. Después de éste (junio 19) hay en la orina huellas de albumina y hematies $t+t$. No damos valor efectivo a los hematies de este último examén; pueden provenir de los lequios a también pueden ser de origen renal, a causa de la sulfadiazina suministrada en el puerperio, no se formularon sino 16 pastas, con un fin profilictico, pero por descuido del servi (io se ke dieron 30 comprimidos.

La preeclampsia tiene, características muy especiales tanto clínicas como de laboratorio. Recalco en todo caso, que una TA alta, como síntoma único no quiere decir preeclampsia, ni mucho menos una TA de tipo oscilante e inestable. 
Esta clase de hipertension oscilante aparece a veces en la menopausia, natural u operatoria y es debida a descquilibrio glandular por aumento de las hormonas hipofisarias al cesar la funci on ovárica ${ }^{3}$. Igual factor puede invocarse en este caso pues bien conocidas son las modificaciones que el embarazo determina en la tiroides, suprarrenales, hipófisis, etc.

Existe un tumor de la corteza suprarrenal, el paraganglioma, que causi crisis hipertensivas y angioespasticas de breve duracion, con sensaciones subje tivas intensas, hipertensión mareada e hiperglicemia, debido a descargas mo mentaneas de adrenalina en el torrente circulatoriot.

Es del (aso aclarar también que la inestabilidad tensional tienc causas como cionales, psíquicas y por acción dirceta del simpatico, sin descartar que esto pue de ser indicio de una hipertensión esencial incipicnte.

En favor del factor nervioso hay que tener en cuenta la labilidad especial del sistema neuro vegetativo de la embarazada y su acción sobre el aparato vascular, sobre todo en los últimos meses, manifestada por hiperexitabilidad simpáticotónica con aumento de la TA por vaso constricción periférica ${ }^{5}$.

Taylor y Best anotan las influencias emocionales, el temor, las preocupaciones, etc., sobre la TA, especialmente sobre la tensión sistólica.

Los estados de agitación psíquica y emocional pueden aumentar los valo res de la TA, en 1, 2 y 3 cents. de Hg. excepcionalmente en más ${ }^{6}$. Pero si esta excitación psiquica tiene lugar en una embarazada, el aumento de la TA no será de 3 cents. de $\mathrm{Hg}$., sino de de 5 o de 6 debido a la mayor exitabilidad del simpratico.

Es fácil comprender el estado emocional de la mujer grávida, en especial tratandose de una muchacha como la de la historia comentada, primigestante, joven, humilde de condición, con miedo del parto, con preocupación por la suerte del hijo, con temor a la clínica, al médico, a las enfermeras y a los exá menes genitales a los que se verí sometida. Todas estas circunstancias determi nan un terreno propicio para los paroxismos de hipertensión.

Se desprende de todos estos datos que el problema de la hipertensión en el embarazo es bastante complejo y obedece a las más diversas causas. Es de mucha importancia la medida de la TA deste los comienzos de la gravidez. Toda alza de la TA en el embarazo debe estudiarse tanto clínicamente como por el control del laboratorio para prevenir las complicaciones serias de todos cono. cidas.

Estados simples de inestabilidad tensional, de causa emocional, merecen atención y tratamiento adecuado pues pueden ser índice de trastornos vagessim páticos o pueden producir accidentes del embarazo como su interrupción por aborto ${ }^{7}$ o por parto prematuro, o el desprendimiento prematuro de la placenta normalmente insertada.

La etiología del presente caso sólo llega a definirse, nos parece, en el curso de una observación más prolongada. Se confirmaría una causa emocional si todo se normalizara una vez que la paciente saliera de su estado puerperal. Pero si después de éste, continuaran las oscilaciones de la TA y hubiere tendencia a la 
hipertension, junto con cofálea y signos de lesion renal podria concluirse que $x$ trata de una afeccion hipertensivia.

1)esafortunadamente estos dates no han podide ser consignados poryue la preciente lue perdida de vista desede su siliela de la clínica.

\section{SIINIIRI()}

So estudis la historia de una paciente que maniliesta grandes oscilaciones de I. I I col los ultimos dias del embarazo, en el parto y en el puerperio. Se h.ne notar la falta de datos anormales en los resultades del laboratorio. So co anchtan espectalmente estas entidades: afeceion hipertensiva, afección renal, prectampsia, paraglanglioma o adenoma de la corteza suprarrenal e inestabilid.el tensional de origen psicosomático.

Se recalca sobre la medida periódica de la TA y sobre la correcta interpre. tacion de los cuadros hipertensivos de la gravidez.

\section{REFERENCIAS}

1. -De Lee Greenhill. Principios y Práctica de Obstetricia. VIII Ed. 1945. p. 440.

2.-Luisada Aldo. Cardiologia. 1945. pp. 719 y 720.

3. - Luisada Aldo. Cardiologia. 1945. pp. 719 y 720.

4. -Luisada Aldo. Cardiologia. 1945. pp. 719 y 720.

5. Stoeckel. Tratado de Obstetricia. III Ed. Tomo I, p. 122.

6. Cossio Pedro. Biblioteca de Semiologia. Aparato Circulatorio. IV Ed. Buenos Aires. p. 295.

70 - Rot. Carballo J. Patologia Psicosomática. Madrid, 1949. p. 731. 